\title{
Morinda citrifolia edible leaf extract enhanced immune response against lung cancer
}

\begin{abstract}
Lung cancer causes 1.4 million deaths annually. In the search for functional foods as complementary therapies against lung cancer, the immuno-stimulatory properties of the vegetable Morinda citrifolia leaves were investigated and compared with the anti-cancer drug erlotinib. Lung tumour-induced BALB/c mice were fed with $150 \mathrm{mg} \mathrm{kg} \bar{i} 1$ or $300 \mathrm{mg} \mathrm{kg} \overline{\mathrm{I}} 1$ body weight of the leaf extract, or erlotinib (50 mg kgi 1 body-weight) for 21 days. The 300 mg kgī 1 body weight extract significantly (and dose-dependently) suppressed lung tumour growth; the extract worked more effectively than the $50 \mathrm{mg} \mathrm{kg} 11$ body weight erlotinib treatment. The extract significantly increased blood lymphocyte counts, and spleen tissue B cells, $\mathrm{T}$ cells and natural killer cells, and reduced the epidermal growth factor receptor (EGFR) which is a lung adenocarcinoma biomarker. The extract also suppressed the cyclooxygenase 2 (COX2) inflammatory markers, and enhanced the tumour suppressor gene (phosphatase and tensin homolog, PTEN). It inhibited tumour growth cellular gene (transformed mouse 3T3 cell double minute 2 (MDM2), V-raf-leukemia viral oncogene 1 (RAF1), and mechanistic target of rapamycin (MTOR)) mRNA expression in the tumours. The extract is rich in scopoletin and epicatechin, which are the main phenolic compounds. The $300 \mathrm{mg}$ kgī 1Morinda citrifolia leaf 50\% ethanolic extract showed promising potential as a complementary therapeutic dietary supplement which was more effective than the $50 \mathrm{mg}$ kgī 1 erlotinib in suppressing lung adenocarcinoma. Part of the mechanisms involved enhancing immune responses, suppressing proliferation and interfering with various tumour growth signalling pathways.
\end{abstract}

Keyword: Lung cancer; Morinda citrifolia 